\title{
Ground motion areas detection (GMA-D): an innovative approach to identify ground deformation areas using the SAR-based displacement time series
}

\author{
Roberta Bonì ${ }^{1}$, Claudia Meisina ${ }^{1}$, Linda Poggio $^{1}$, Alessandro Fontana ${ }^{2}$, Giulia Tessari ${ }^{3}$, Paolo Riccardi ${ }^{3}$, \\ and Mario Floris ${ }^{2}$ \\ ${ }^{1}$ Department of Earth and Environmental Sciences, University of Pavia, 27100, Pavia, Italy \\ ${ }^{2}$ Department of Geosciences, University of Padua, 35131, Padua, Italy \\ ${ }^{3}$ Sarmap SA, Cascine di Barico, Purasca, Switzerland
}

Correspondence: Roberta Bonì (roberta.boni01@universitadipavia.it)

Published: 22 April 2020

\begin{abstract}
In this work, an innovative methodology to generate the automatic ground motion areas mapping is presented. The methodology is based on the analysis of the Synthetic Aperture Radar (SAR)-based displacement time series. The procedure includes two modules developed using the ModelBuilder tool (ArcGis). These modules allow to identify the ground motion areas (GMA) using only one dataset and the persistent GMA (PGMA) considering the different monitored periods and datasets. These areas represent clusters of targets characterized by the same displacement time series trend. The procedure was tested using different sensors such as ERS1/2, ENVISAT, COSMO-SkyMed and Sentinel-1 covering the periods, 1992-2000, 2003-2010, 2012-2016 and 2014-2017, respectively, over an area of about $500 \mathrm{~km}^{2}$ in the Venetian-Friulian coastal Plain (NE Italy). The resulting mapping allows to detect priority areas where to address further in situ investigations such as to verify the presence of localized buried landforms.
\end{abstract}

\section{Introduction}

Different geohazard-mapping methodologies have been previously developed to exploit Advanced-Differential Interferometric Synthetic Aperture Radar (A-DInSAR) (Meisina et al., 2008; Lu et al., 2012; Di Martire et al., 2016; Barra et al., 2017). In many cases, to produce these maps the analysis is mainly based in the use of average LOS velocity and stability velocity thresholds. However, considering the recent improvements in the displacement time series, especially the reduced revisit time of recent satellites (e.g. 6-12 d for the Sentinel data), we propose a novel methodology for the automatic mapping of ground motion areas implemented using the ModelBuilder tool (ArcGis) and tested using ERS-1/2, ENVISAT, COSMO-SkyMed and Sentinel-1 covering the periods, 1992-2000, 2003-2010, 2012-2016 and 2014-2017 acquired over the Venetian-Friulian coastal Plain (NE Italy). The test area is a representative site characterized by a general long-term subsidence (average rate $0.4-0.5 \mathrm{~mm} \mathrm{yr}^{-1}$ ), mainly related to crustal flexuring and sediment compaction including much stronger values recently measured in specific areas with peculiar subsoil conditions, such as a buried incised river valley filled with softer sediments (e.g. Fontana et al., 2010; Floris et al., 2019). The obtained results are helpful for scientists and authorities in charge of land use planning in order to detect different geohazards on the base of the displacement time series trend using big data.

\section{Study area}

The study area covers about $500 \mathrm{~km}^{2}$ in the Venetian-Friulian coastal Plain (NE Italy) (Fig. 1). This plain represents the eastern sector of the Po Plain and is composed by deposits of the Alpine rivers (Castiglioni, 1999). The area is characterized by Late-Quaternary deposits composed by alluvial and coastal sediments. In particular, the northern part of the study area is characterized by a buried fluvial incision eroded by 


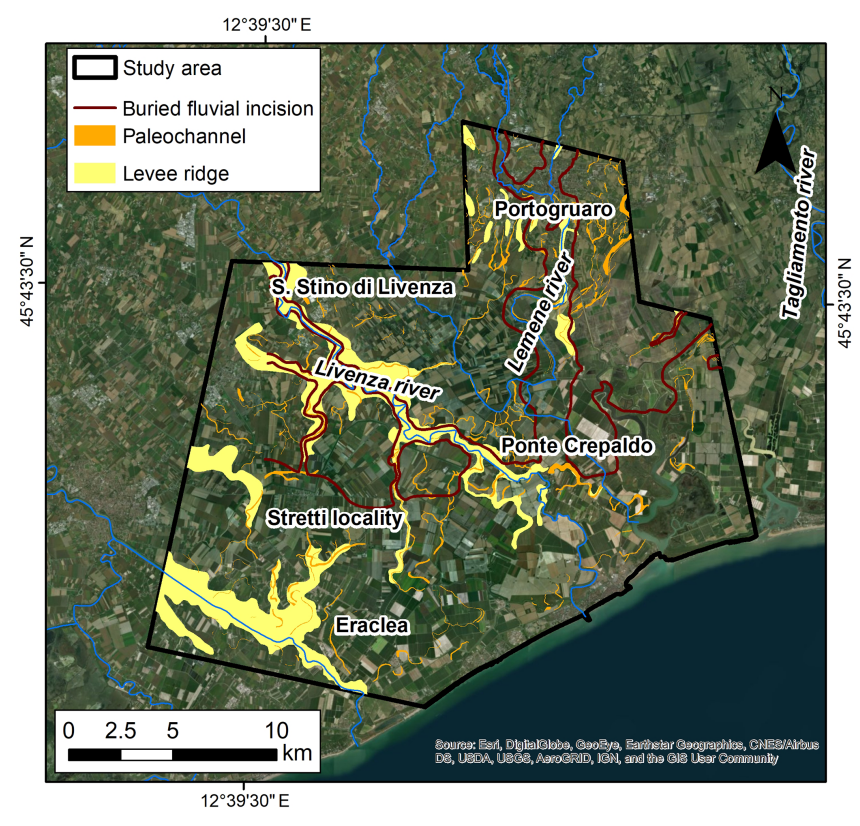

Figure 1. Geographical location.

the Tagliamento River during the Late Glacial that has been occupied by the Lemene river since Middle Age (Fontana et al., 2008). South of Portogruaro the buried incised valley has been filled during the Holocene by fluvial and lagoon deposits consisting of softer sediments and peat layers, susceptible to land subsidence.

\section{Materials and methods}

\subsection{Multi-Temporal A-DInSAR data}

Available Synthetic Aperture Radar (SAR) data consists of ERS-1/2, ENVISAT and COSMO-SkyMed and Sentinel-1 scenes acquired in descending mode allowing to cover a significant time span of analysis of about 25 years over the study area. ERS-1/2 and ENVISAT data covers the time interval from June 1992 to December 2000 and from April 2003 to July 2010. COSMO-SkyMed (CSK) data covers the time interval from February 2012 to January 2016. Sentinel-1 data covering the time interval from December 2014 to July 2017 are also considered.

Interferometric data derived by PS-InSAR ${ }^{\mathrm{TM}}$ (Ferretti et al., 2001; Costantini et al., 2017) processing of ERS-1/2 and ENVISAT SAR images, were provided by the Italian Ministry of Environment in the framework of a "Not Ordinary Plan of Remote Sensing" project (http://www.pcn. minambiente.it/mattm/en/, last access: 2 March 2020). CSK and Sentinel-1 data were processed using the PS-InSAR (PSI) module implemented in SARscape software developed by sarmap SA. The resulting PS velocity maps obtained from the processing are shown in Fig. 2.

\subsection{Ground motion areas (GMA) and persistent ground motion areas (PGMA) detection}

In the current study, a novel automatized approach is developed using ModelBuilder ${ }^{\mathrm{TM}}$ in ArcGIS 10.4.1 (ESRI software), in order to delineate the preliminary GMA using the methodology proposed by Bonì et al. (2016) and the Persistent GMA (PGMA), representing the areas characterized by continuous movement using multi-temporal A-DInSAR data such as ERS-1/2, ENVISAT, Cosmo-SkyMED (CSK) and Sentinel-1 data. In particular, GMA represent clusters of a minimum 3 of measuring points, with a maximum distance of $25-50 \mathrm{~m}$, including the same trends such as linear, nonlinear and seasonal, identified using the principal component analysis (PCA). PGMA are moving areas identified using all the available SAR datasets, that can be characterized by deceleration and are not necessarily characterized by constant trends in time.

The developed geoprocessing workflow is composed by two modules and it was built using a Visual programming language (Allen, 2011). The benefit of these geoprocessing models is the automatic and standardized identification of preliminary GMA and PGMA. The architecture of the automatized approach consists of two models (Fig. 3).

The ArcGIS (ESRI) ModelBuilder ${ }^{\mathrm{TM}}$ runs the models with different datasets. In particular, the first model is named GMA-D (ground motion areas detection) and it is developed for the identification of the preliminary GMA. The input data is the dataset of the principal score (PC) filtered using a threshold for the significant PC score selection (Bonì et al., 2016). The PC score is an output of the PCA, obtained for each target and useful to evaluate the correlations with the principal components in the whole dataset (Bonì et al., 2018); the higher values correspond to higher correlations with the analyzed PC (Jolliffe and Cadima, 2016).

The PC score dataset of different components of ground motion (e.g. first, second and third ones) can be used as input in the model. The first part of the GMA-D model is the creation of buffer zones around the selected measuring points (PC score buffer) and then, clusters are delineated using the dissolve (PC score cluster) and multi-part to single part (PC score clusters) geoprocessing tools of ArGIS (Fig. 3a). Finally, a spatial join is performed to count the number of PC score points located within each preliminary GMA in order to use filters to select only the significant GMA.

The second model is named PGMA-D (persistent ground motion area detection) and it is aimed to detect the GMA that are persistent using A-DInSAR data including different monitored periods and sensors. In particular, the model presented in Fig. $3 b$ is based on the analysis of ERS-1/2, ENVISAT, Cosmo-SkyMED (CSK) and Sentinel-1 data but it can be used to run on any dataset. In the second model, the input data are GMA detected using the different sensors (e.g GMA ERS, GMA ENV, GMA CSK and GMA Sentinel). The model is based on the intersection between the GMA previ- 

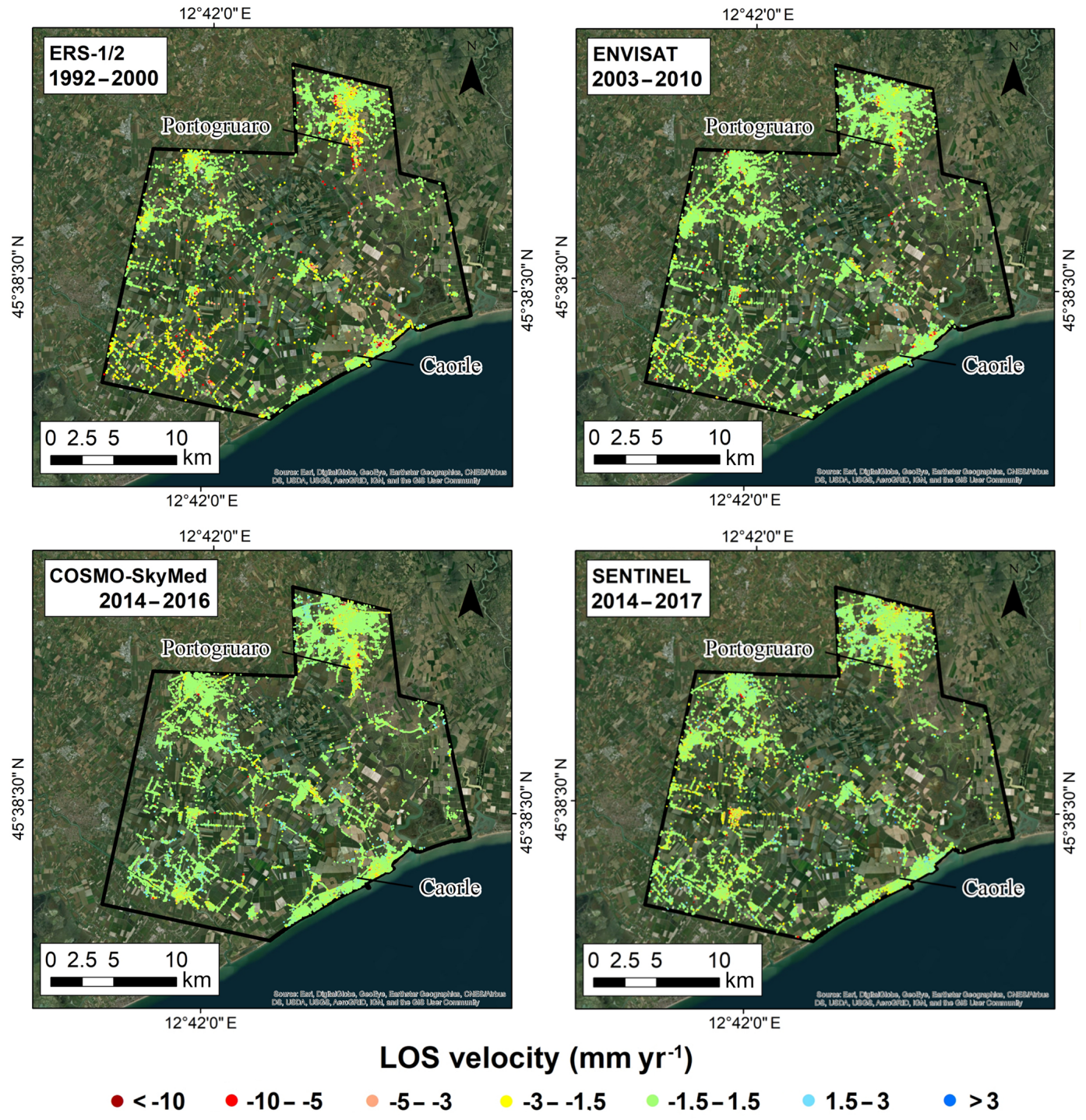

Figure 2. PS velocity maps ( $\mathrm{mm} \mathrm{yr}^{-1}$ ) derived by PSI processing of ERS-1/2 (1992-2000), ENVISAT (2003-2010) and COSMO-SkyMed (2014-2016) and Sentinel (2014-2017) SAR data. The black box represents the study area.

ously identified and the model output is the delineation of the areas of intersection between the different input GMA data.

\section{Results}

\subsection{Ground motion areas (GMA) detection}

GMA delineation was performed using ERS-1/2, ENVISAT, Cosmo-SkyMED (CSK) and Sentinel-1 data by applying the GMA-D model. For each dataset a different number of GMA were recognized using the retrieved principal component of ground motion.

PCA analysis of ERS-1/2 displacement time series allowed to detect three principal components (Fig. 4). The first represents a linear land subsidence trend, meanwhile the second and third show non-linear trends highlighting an uplift and a cyclic trend, respectively. Even in the case of ENVISAT data, three components of the ground motion were obtained. In this case, the first and second are characterized by a linear land subsidence trend with a different velocity, the third component is characterized by an evident cyclic component. By using the COSMO-SkyMed data, three principal components were detected showing land subsidence, noisily uplift and cyclic trend, respectively. Finally, by applying the same methodology on the Sentinel data, three principal components of the ground motion were detected: the first shows a linear land subsidence, the second and third are noisily and are characterized by an uplift and a cyclic trend, respectively.

The obtained PC score filters were used to delineate the GMA using the GMA-D model, then the GMA were used to identify the persistent GMA in the monitored period (1992- 

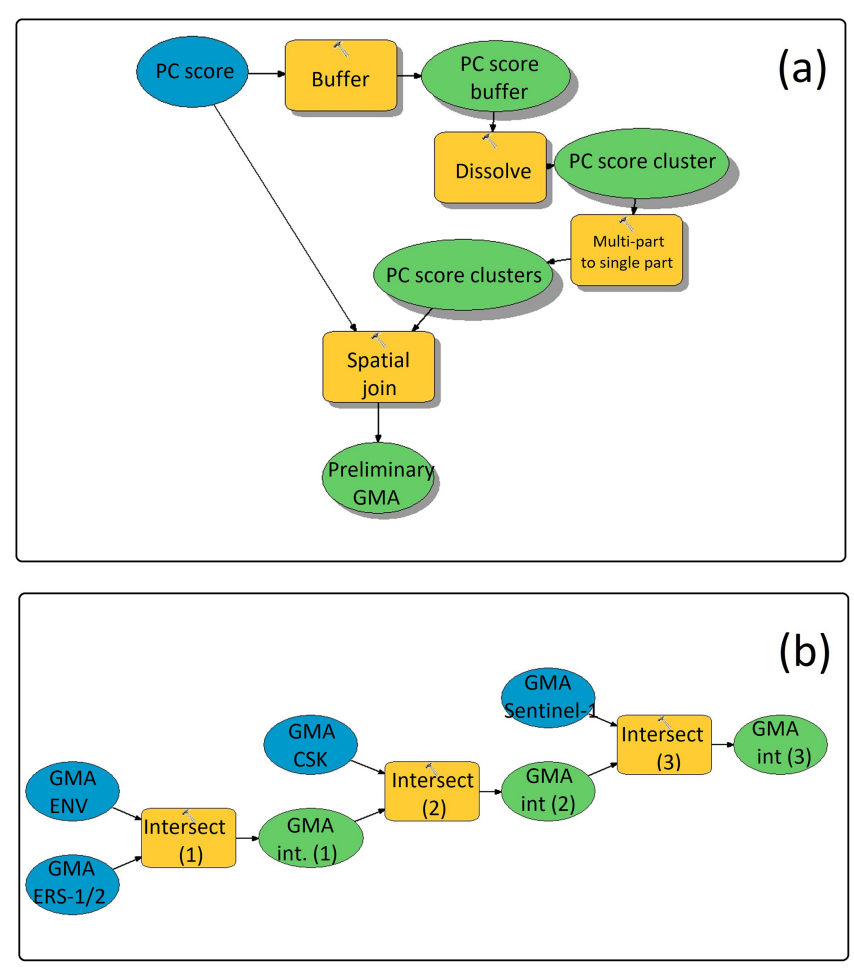

Figure 3. Geoprocessing workflow of the GMA-D and PGMA-D models which allow to create preliminary GMA (a) and persistent GMA (b), respectively.

2017) using the PGMA model as described in Sect. 3.2. The analysis of the ERS-1/2 data gives insight about GMA detected using only the first component and these areas are mainly localized in the northern sector and in the south-west part of the study area (Fig. 5). GMA detected using the ENVISAT data belong to the PC1, PC2 and PC3. PC1 ground motion areas are mainly localized in Portogruaro, meanwhile the PC2 ground motion areas are along the coastline. The PC3 ground motion areas are not very well diffused and they are mainly localized in the coastal area (Fig. 5). By analysing CSK data, the GMA detected belong to the first and third component. In this case, GMA show a greater extension with respect to the ones detected in the previous periods (Fig. 5). By analysing the Sentinel-1 data, GMA detected using the PC2 are not evident, meanwhile PC1 and PC 3 are observed in Portogruaro and along the coastline, respectively (Fig. 5).

\subsection{Persistent Ground motion areas (PGMA) detection}

In order to detect the significant GMA moving during the entire monitored period (1992-2017) and corresponding to land subsidence processes, the second model PGMA-D described in Sect. 3.2 was applied. Therefore, the intersection areas (persistent GMA) of the GMA detected using the first principal component of the ERS-1/2, ENVISAT, Cosmo-SkyMED (CSK) and Sentinel-1 data were identified. The results give insight in 13 persistent GMA (PGMA) continuously moving in the monitored time (Fig. 6). From these PGMA, seven areas are located in Portogruaro within the buried incision of the Tagliamento river (from PGMA1 to PGMA7). The PGMA8 is located in San Stino di Livenza within a buried paleochannel of the Livenza river (Floris et al., 2019). The PGMA9 is located in Stretti locality. The PGMA10 is placed near Ponte Crepaldo, in correspondence of a fluvial ridge, meanwhile PGMA11 and PGMA12 are localized in Eraclea and in the industrial zone of Eraclea in correspondence of a fluvial ridge and in the alluvial plain of the Piave river. Finally, the PGMA13 is placed in the area of La Salute di Livenza insisting on a fluvial ridge of the Livenza river.

Figure 6 shows the average displacement time series trend of each PGMA. The cumulated displacement in the detected PGMA reaches values of about $60-80 \mathrm{~mm}$ in the period from 1992-2016.

\section{Discussions}

The results give insight about the capability of the methodology to detect ground motion areas from 1992-2017 characterized by linear and non-linear deformation patterns, induced by natural and man-induced processes such as sediment compaction, land subsidence due to load of new buildings, and seasonal ground motion due to groundwater level variations.

\section{Conclusions}

An automatic mapping of the ground motion processes in the coastal Plain of NE Italy, based on the methodology proposed by Bonì et al. (2016), was implemented for the identification of GMA and PGMA using multi-temporal A-DInSAR data. The resulting mapping allows to generate a mapping of priority areas for engineering geological studies and where to address further in situ investigations.

Data availability. All data generated or analysed during this study are included in this published article and are available upon request.

Author contributions. RB: Conceptualization, Methodology, Formal Analysis, Validation, Writing - Original Draft. CM: Conceptualization and Methodology. LP: Formal Analysis and Validation. AF: Formal Analysis and Validation of the geomorphological data. GT and PR: Formal Analysis and Validation of the Multi-Temporal A-DInSAR data. MF: Conceptualization, Methodology, Validation of the Multi-Temporal A-DInSAR data and Project coordination. All co-authors Writing - Review and Editing. 

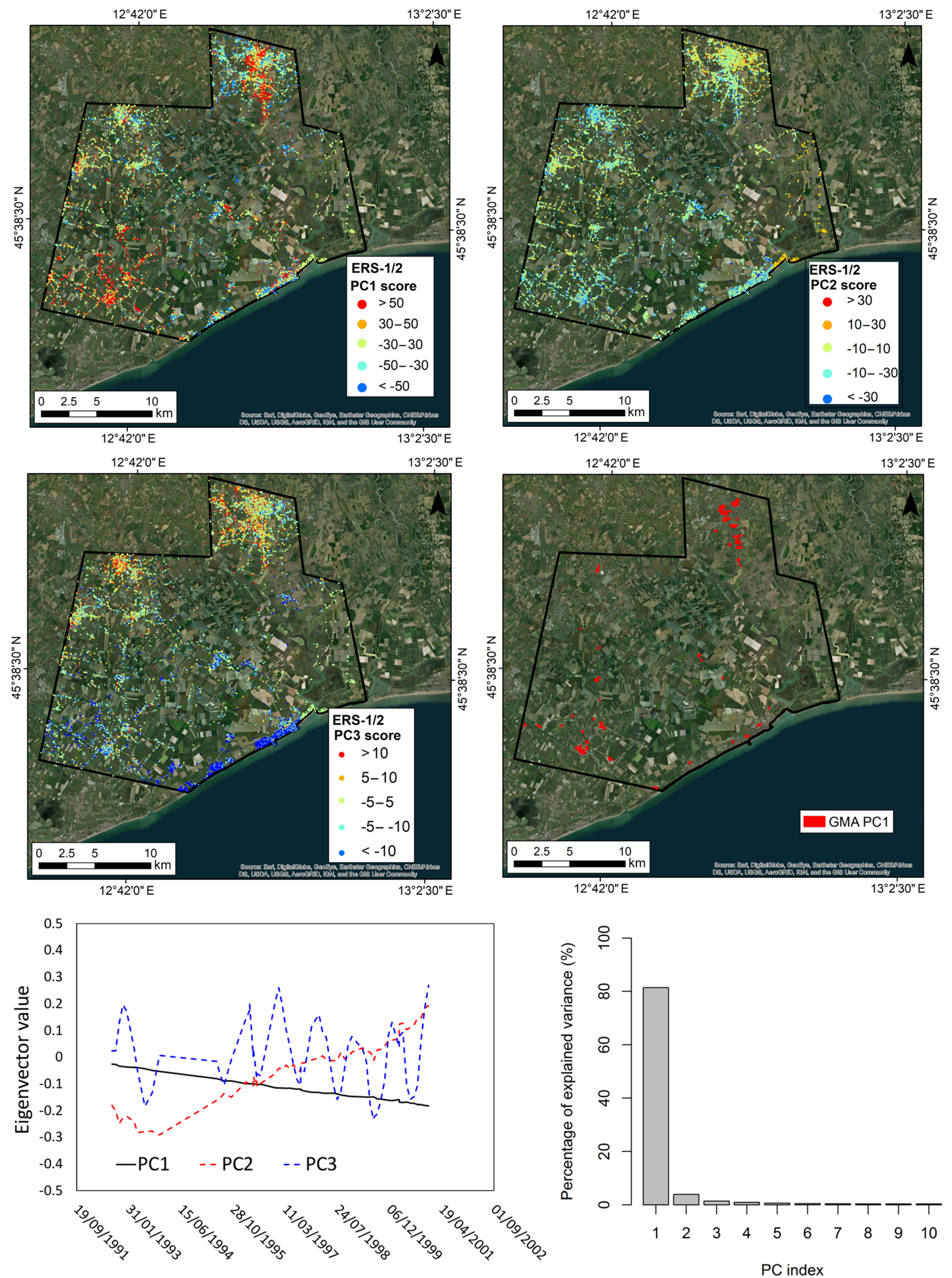

Figure 4. Principal component score maps and GMA mapping obtained using ERS-1/2 data for the period 1992-2000. Eigenvectors of the principal components (PC) and the percentage of the explained variance are also reported. 

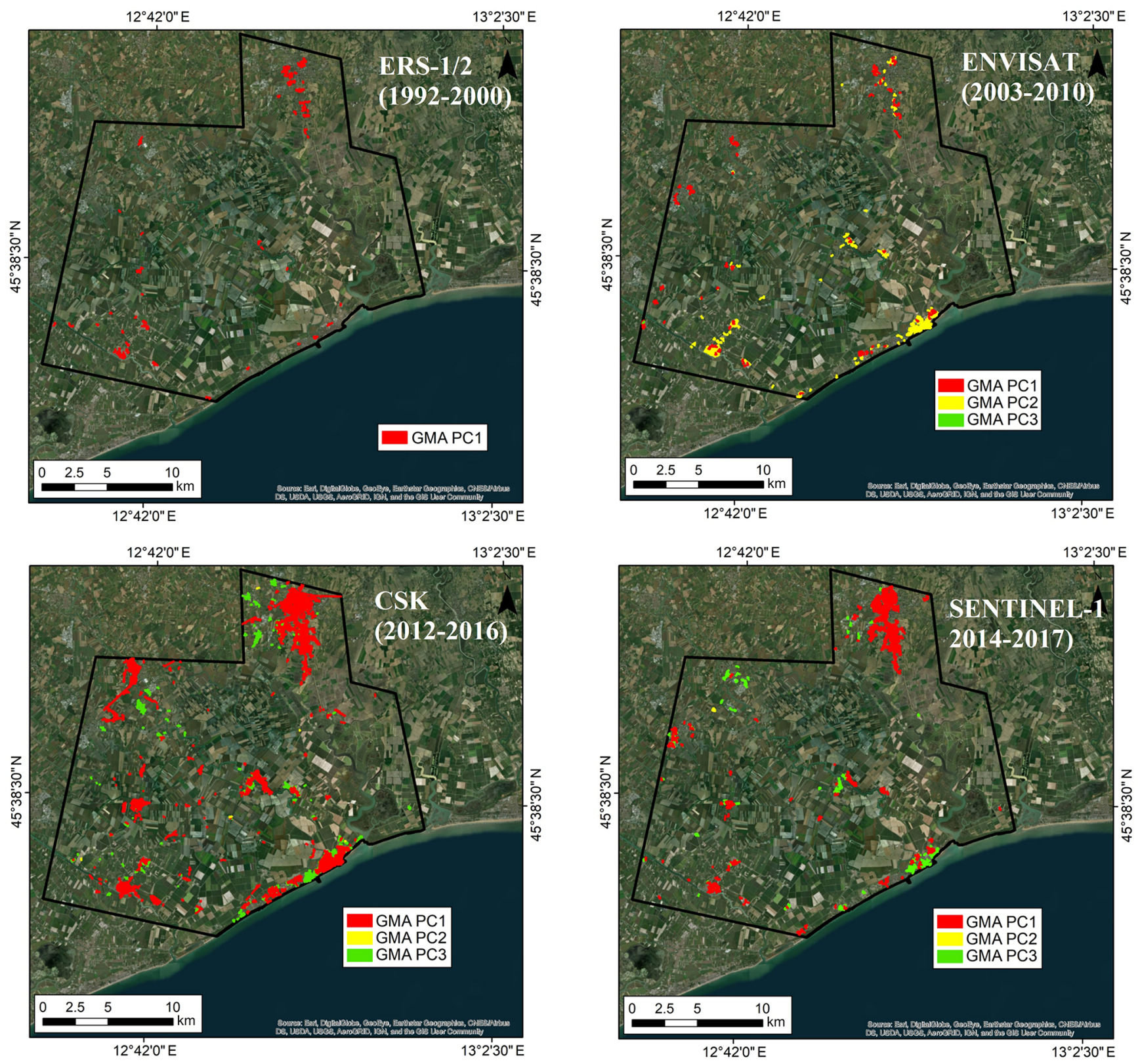

Figure 5. GMA detected in the different monitored periods. 

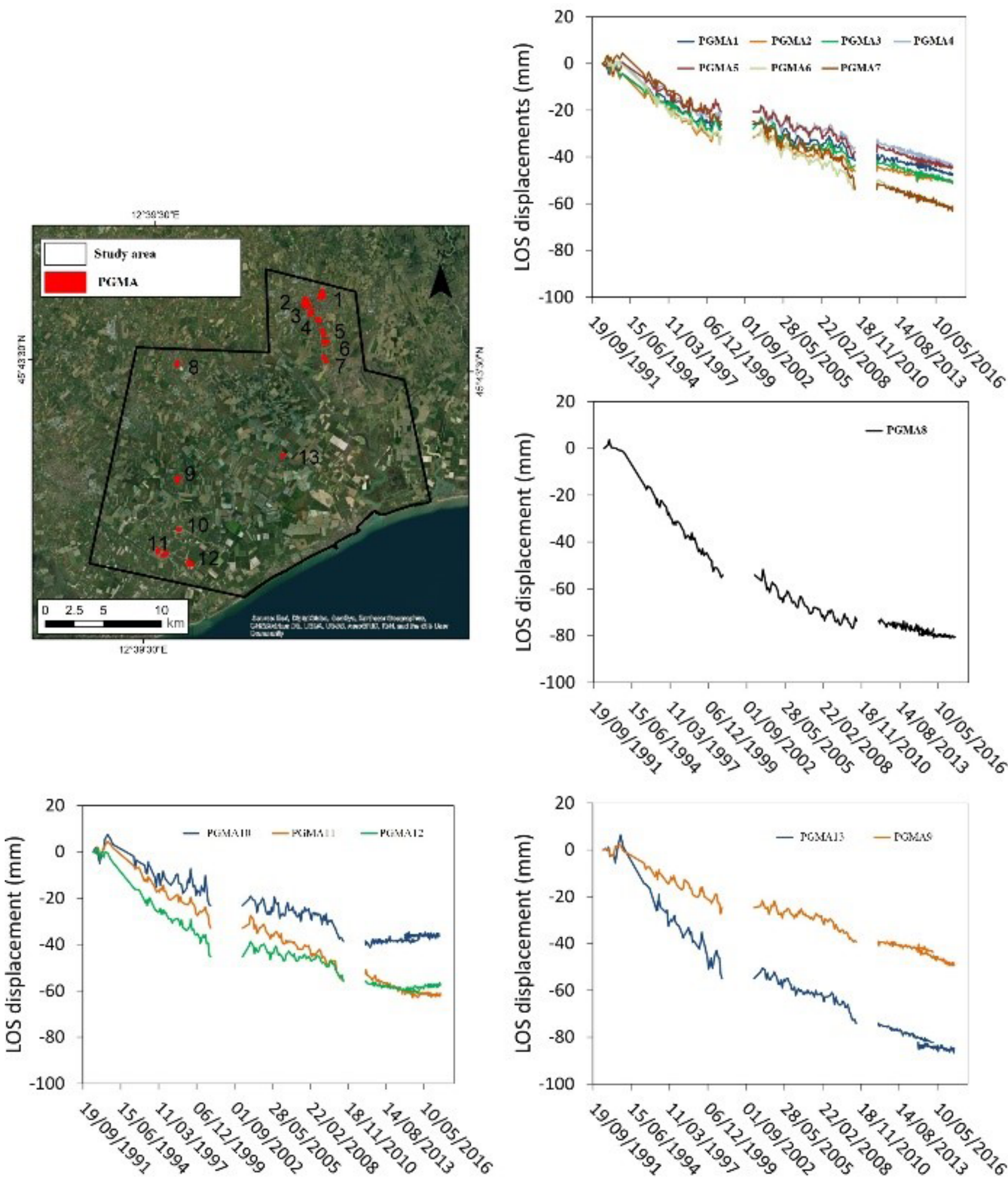

Figure 6. Persistent GMA detected using ERS-1/2, ENVISAT, Cosmo-SkyMED (CSK) and Sentinel-1 data in the period from $1992-2017$. The LOS displacement time for each persistent GMA are also reported. 
Competing interests. The authors declare that they have no conflict of interest.

Special issue statement. This article is part of the special issue "TISOLS: the Tenth International Symposium On Land Subsidence - living with subsidence". It is a result of the Tenth International Symposium on Land Subsidence, Delft, the Netherlands, 17-21 May 2021.

Acknowledgements. The research was funded by University of Pavia in the framework of a research grant award "assegno di tipo A premiale" for research activities at the Dept. of Earth and Environmental Sciences, within the research project entitled "Sustainable groundwater resources management by integrating ADInSAR derived monitoring and flow modeling results (RESERVOIR)" assigned to Roberta Bonì in March 2019 (supervisor Claudia Meisina). The activity has been developed in the framework of the Project "Subsidence zonation through space-borne SAR interferometry as a tool for geomorphological and geological mapping in coastal plain environments" (P. I. Mario Floris), financially supported by the Department of Geosciences of the University of Padua (Italy).

Financial support. This research has been supported by the Università degli Studi di Pavia, Dipartimento di Scienze della Terra e dell'Ambiente (grant no. Assegno di tipo A premiale: "Sustainable groundwater resources management by integrating A-DInSAR derived monitoring and flow modeling results (RESERVOIR)" assigned to Roberta Bonì in March 2019) and the Department of Geosciences of the University of Padua (Italy) (Project "Subsidence zonation through space-borne SAR interferometry as a tool for geomorphological and geological mapping in coastal plain environments" (P. I. Mario Floris)).

\section{References}

Allen, D. W.: Getting to know ArcGIS modelBuilder, Esri Press, 336 pp., 2011.

Barra, A., Solari, L., Béjar-Pizarro, M., Monserrat, O., Bianchini, S., Herrera, G., Crosetto, M., Sarro, R., González-Alonso, E., Mateos, R. M., Ligüerzana, S., López , C., and Moretti, S. : A Methodology to Detect and Update Active Deformation Areas Based on Sentinel-1 SAR Images, Remote Sens., 9, 1002, https://doi.org/10.3390/rs9101002, 2017.
Bonì, R., Pilla, G., and Meisina, C.: Methodology for detection and interpretation of ground motion areas with the ADInSAR time series analysis, Remote Sens., 8, 103-126, https://doi.org/10.3390/rs808, 2016.

Bonì, R., Bosino, A., Meisina, C., Novellino, A., Bateson, L., and McCormack, H.: A methodology to detect and characterize uplift phenomena in urban areas using Sentinel-1 data, Remote Sens., 10, 144-166, 2018.

Castiglioni, G. B.: Geomorphology of the Po plain, Comitato glaciologico italiano, Suppf. Geogr. Fis. Dinam. Qual. III, T.3, 7-20, 12 figg., 1999.

Di Martire, D., Novellino, A., Ramondini, M., and Calcaterra, D.: A-differential synthetic aperture radar interferometry analysis of a deep seated gravitational slope deformation occurring at Bisaccia (Italy), Sci. Total Environ., 550, 556-573, 2016.

Floris, M., Fontana, A., Tessari, G., and Mulè, M.: Subsidence Zonation Through Satellite Interferometry in Coastal Plain Environments of NE Italy: A Possible Tool for Geological and Geomorphological Mapping in Urban Areas, Remote Sens., 11, 26 47, 2019.

Fontana, A., Mozzi, P., and Bondesan, A.: Alluvial megafans in the Venetian-Friulian Plain (north-eastern Italy): Evidence of sedimentary and erosive phases during Late Pleistocene and Holocene, Quaternary Int., 189, 71-90, 2008.

Fontana, A., Mozzi, P., and Bondesan, A.: Late pleistocene evolution of the Venetian-Friulian Plain, Rendiconti Lincei, 21, 181196, 2010.

Jolliffe, I. T. and Cadima, J.: Principal component analysis: a review and recent developments, Philos. T. R. Soc. A, 374, 2065, https://doi.org/10.1098/rsta.2015.0202, 2016.

Lu, P., Casagli, N., Catani, F., and Tofani, V.: Persistent Scatterers Interferometry Hotspot and Cluster Analysis (PSI-HCA) for detection of extremely slow-moving landslides, Int. J. Remote Sens., 33, 466-489, 2012.

Meisina, C., Zucca, F., Notti, D., Colombo, A., Cucchi, A., Savio, G., Giannico, C., and Bianchi, M.: Geological Interpretation of PSInSAR Data at Regional Scale, Sensors, 8, 7469-7492, https://doi.org/10.3390/s8117469, 2008. 